\title{
Key directions for determining and reducing the level of conflict of the team
}

\author{
Natalya Nagibina $^{1, *}$, Lyudmila Komyshova ${ }^{1}$, Kirill Sklyarov ${ }^{1}$, and Anna Sviridova ${ }^{1}$ \\ ${ }^{1}$ Voronezh State Technical University, Moscow Avenue, 14, Voronezh, 394026, Russia
}

\begin{abstract}
The article discusses the possibility of determining and reducing the level of conflict of the team. The aim of the work is to highlight the appropriate tools and the main directions of reducing the level of conflict of the team. The subject of the study is the behavior of the organization's employees in a conflict situation, the object is JSC "DOM.RF" it is a Russian organization specializing in the provision of banking services. The study is based on the use of the methods of K. Thomas and R. Kilmann to determine the level of conflict of personality. On its basis had obtained the distribution of employees of one of the structural divisions of the organization according to such styles of behavior in a conflict as confrontation, cooperation, compromise, evasion and adaptation. The obtained results made it possible to propose integral indicators for assessing the level of conflict and team coordination. Their value for the examined organization's structural subdivision indicates the dominance of employees who shows unconstructive behavioural patterns in conflict situation preventing this situation being solved. Taking to account the specifics of the activities of the examined staff the results are quite acceptable but suggest mandatory prevention of the increase of conflict of the examined team. Among the main directions of reducing the level of conflict of the team is proposed: identifying the level of conflict of employees according to the ThomasKilmann methodology, determining the levels of conflict and coordination of the team; using of psychological diagnosis of personality conflict during hiring for a vacant position; conducting psychological trainings for employees of a structural unit or organization as a whole with the aim to manage their behavior in a conflict situation.
\end{abstract}

\section{Introduction}

Effective management of any organization depends on many external and internal factors. However, it can be argued that the psychological aspect of the relationship of members of any team acquires fundamental importance.

Currently, scientific knowledge has many definitions of the concept of conflict. In the famous work on sociology of conflict of A.G. Zdravomyslov the conflict is defined as a "cell of social being" which is necessary because in any society there are opposing values and norms that oppose interests and needs [1].

\footnotetext{
${ }^{*}$ Corresponding author: nagibina.natalya@yandex.ru
} 
A modern psychological dictionary defines conflict as "a difficult to resolve contradiction that is associated with acute emotional experiences." The dictionary defines the main forms of conflict: intrapersonal, interpersonal and intergroup [2].

The authors of the fundamental work on conflictology A.Ya. Antsupov and A.I. Shepilov defines conflict as follows: "Conflict is understood as the most acute way to resolve significant contradictions that arise in the process of interaction, which consists in counteracting the subjects of conflict and usually accompanied by negative emotions. From this definition it is obvious that the presence of only one condition, that is opposition or negative feelings does not constitute a classic conflict situation. The authors attribute this type of situation to pre-conflict. The most controversial in this definition is whether in the conflict is included the focus on its removal as a way to resolve contradictions [3].

Another major scientist who studies conflicts, B.I.Hasan, offers the following definition of conflict: "Conflict is such a characteristic of interaction in which actions that cannot coexist in an unchanged form interdeterminate and interchange each other and requiring a special organization for this. It is important to consider that the action can be considered both externally and internally. At the same time, any conflict is an actualized contradiction, that is opposing values, attitudes, motives embodied in the interaction. "In the above definition is making an emphasis that conflict is a special characteristic of the interaction of the parties in which collision and contradictions are necessarily present [4].

All the above definitions are fairly close in identifying the main components and signs of conflict but not one of them covers the entire breadth of the problem scope of the conflict phenomenon.

On their basis the main criteria for conflict can be distinguished.

Firstly, it is subjectivity what means the presence of at least one participant in the conflict. For example, in an intrapersonal conflict, different parts of "I" collide.

Secondly, the presence of a difficult to resolve contradiction what means in any conflict there are opposing needs, concepts, interests or motives.

And finally, the third essential criterion for any conflict is a clash, a confrontation. Almost all authors argue that the state before the collision is not a conflict yet.

G. Simmel believed that "conflict ... is designed to solve any dualism, it is a way to achieve a kind of unity, even if it achieved by the cost of destroying of one of the parties of the conflict" [5].

It should also be noted that the concept of conflict at the moment has acquired a negative coloration, which is controversial. So conflict researcher Coser wrote about the positive functions of this phenomenon. The conflict from the point of view of Coser can relieve tension between the warring parties and can also perform communicative and connecting functions [6].

Conflicts, according to Coser, affect to the social field, establish clear boundaries between groups, strengthen normative behavior and the internal unity of groups.

The ability to influence the behavior of employees in a conflict situation is relevant for any organization due to the fact that only a constructive resolution of the conflict allows to be used to improve the socio-psychological climate in the team, to develop an open, kind and friendly atmosphere in a local structural unit and the organization as a whole.

\section{Materials and methods}

Analysis of behavior in conflict situations was considered for the experts of the contact center of JSC «DOM.RF».

JSC "DOM.RF" was founded in 1997. On the basis of the joint-stock company in 2015 a unified institution for the development of the housing sector was created. All shares of the corporation belong to the state represented by Federal Property Management Agency 
(Rosimuschestvo). «DOM.RF» implements government initiatives aimed to improving the quality and affordability of housing, including through mortgages, civilized rents and the formation of a comfortable urban environment.

In 2018, as part of the project to centralize the operational functions of "DOM.RF", the Unified Service Center (USC) was created in Voronezh. Accounting and taxation, mortgage business support, operational and cash support, a contact center, information technology, underwriting, data quality control, personnel management were transferred to Voronezh. Today, 670 people work in the USC; it is planned to create about 1,200 jobs.

The contact center is one of the structural divisions of JSC "DOM.RF" the main tasks of which are:

- receiving incoming calls and informing citizens about the issues of banking services, mortgage lending, allocation and registration of land;

- advising clients in writing via chat;

- making outgoing calls in order to inform the organization's customers about existing discounts, financing programs, etc.;

- assisting bank customers in a diverse range of emerging issues.

Currently it has about seventy employees. In the near future it is planned to expand the staff to 200 people.

The distribution of call center employees by job title is graphically presented in Figure 1 .

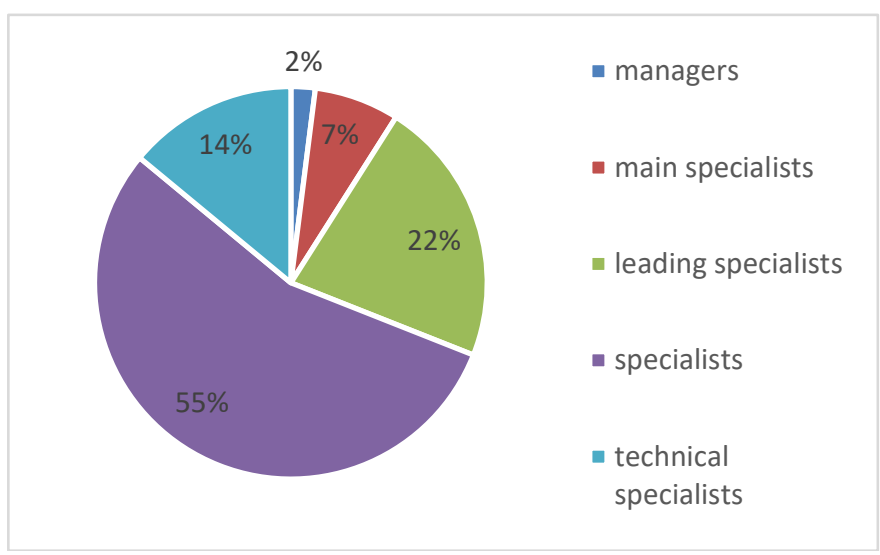

Fig. 1. Distribution of employees of the call center of JSC "DOM.RF" by positions

The share of employees among those whose behavior in the conflict was studied is $55 \%$ which is more than half and the specifics of their work which is to inform the organization's clients on a wide range of issues from banking services to the allocation and registration of land so it suggests that the occurrence of conflicts most likely to take place among this group.

The determination of the level of conflict was carried out on the basis of the methodology which had developed by the English psychologist Ken Thomas and Ralph Kilmann in 1972 [7].

Respondents were asked a questionnaire consisting of 30 statements related to different ways of human behavior in a conflict situation. From each pair of statements only one option was chosen which is the most acceptable according to the respondent.

The Thomas-Kilmann methodology allows to obtain a quantitative assessment of each of the five possible styles of behavior in a conflict situation that are presented in Figure 2. 


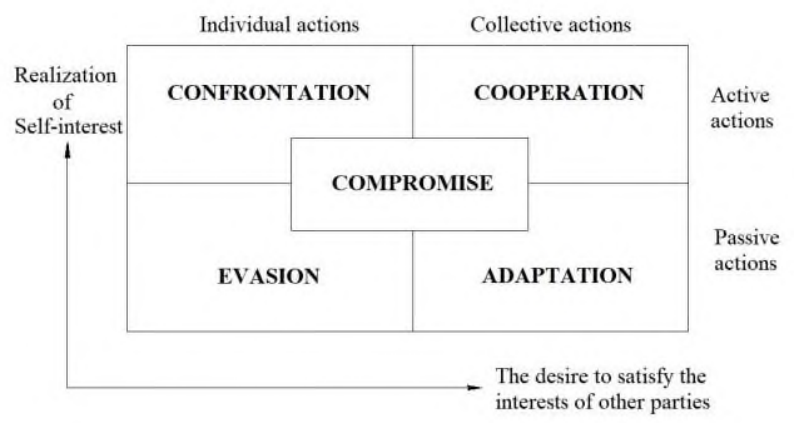

Fig. 2. Styles of behavior in a conflict situation

The number of points characterizing the selected behaviors can vary from 0 which indicates the absence of this style of behavior in the conflict to 12 which indicates the maximum intensity of this style of behavior in a conflict.

The level of intensity of this style of behavior was assessed using the scale depending on the total number of points by the respondent during characterizing a particular style of behavior in a conflict presented in table 1.

Table 1. Scale for assessing styles of behavior in conflict

\begin{tabular}{|c|c|l|}
\hline $\begin{array}{c}\text { Degree of } \\
\text { manifestation }\end{array}$ & $\begin{array}{c}\text { The number of points } \\
\text { according to the } \\
\text { methodology of Thomas- } \\
\text { Kilmann }\end{array}$ & Characteristic \\
\hline Low & $0-4$ & $\begin{array}{l}\text { The absence of the } \\
\text { considered style of } \\
\text { behavior or its minimal } \\
\text { intensity }\end{array}$ \\
\hline Medium & $5-8$ & $\begin{array}{l}\text { The average intensity of } \\
\text { the considered behaviors }\end{array}$ \\
\hline High & $9-12$ & $\begin{array}{l}\text { The maximum intensity of } \\
\text { the considered behaviors }\end{array}$ \\
\hline
\end{tabular}

Assessment of the selected styles of behavior in the conflict was carried out by 15 specialists of the contact center. The sample of respondents was carried out randomly and its volume amounts to $47 \%$ of the total number of specialists and allows to conclude that it is possible to extend the results of the study to the general population which is all contact center specialists.

\section{Results and Discussion}

The distributions of contact center specialists were obtained by the number of points and by the level of intensity of a certain style of behavior in the conflict for each of the five analyzed styles of behaviors.

Samples of the obtained distributions for such style of behavior in a conflict situation as confrontation are presented in Figure 3. 

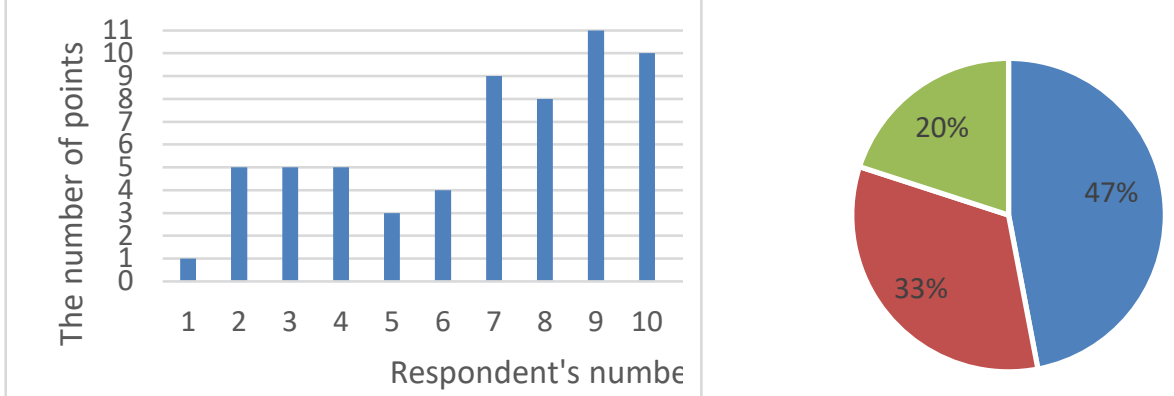

Fig. 3. Distribution of contact center specialists by the number of points and the level of intensity of such a style of behavior in a conflict as confrontation

A fifth part of the contact center specialists are characterized by a great interest in conflict resolution and an involvement in it. However the position of the other side will not be taken into account. A third part of the contact center specialists are characterized by an average interest in conflict resolution and an involvement in it. The position of the conflicting side will be taken into account but to a lesser extent than their own interests. For almost half of the specialists the interest in conflict resolution and involvement in it will be minimal.

Distributions of contact center specialists by the number of points and by the level of intensity of such style of behavior in a conflict as cooperation are presented in Figure 4.

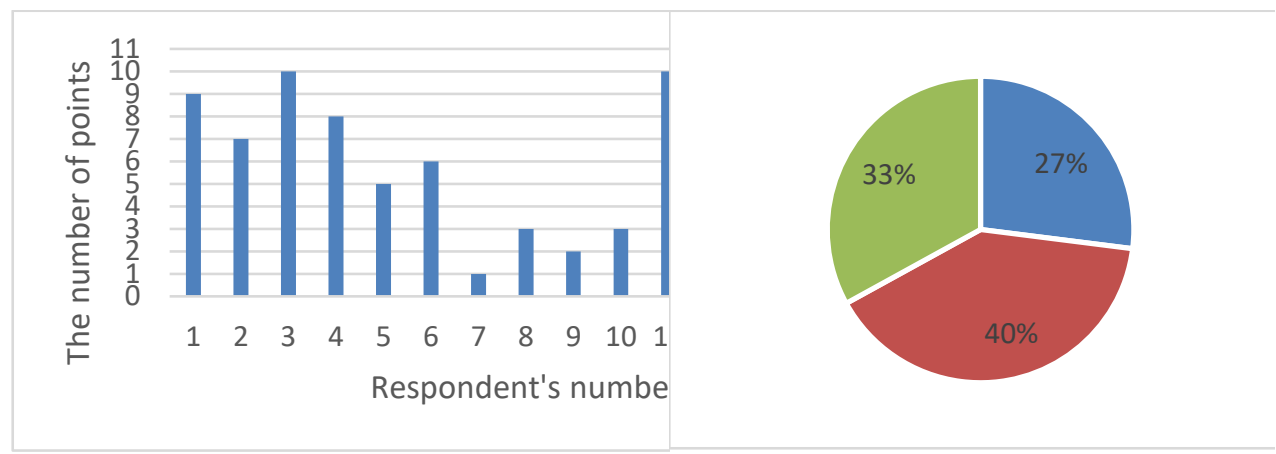

Fig. 4. Distribution of contact center specialists by the number of points and by the level of expression of such style of behavior in a conflict as cooperation

The result indicates that $40 \%$ of specialists in a conflict in most cases will try to resolve it in a partial interaction with colleagues. $33 \%$ of respondents perceive the conflict as a normal event a positive resolution of which is possible based on the opinions of each of the conflicting parties. But $27 \%$ of the contact center specialists are not ready to cooperate with colleagues in a conflict.

Distributions of contact center specialists by the number of points and by the level of intensity of such style of behavior in a conflict as a compromise are presented in Figure 5. 


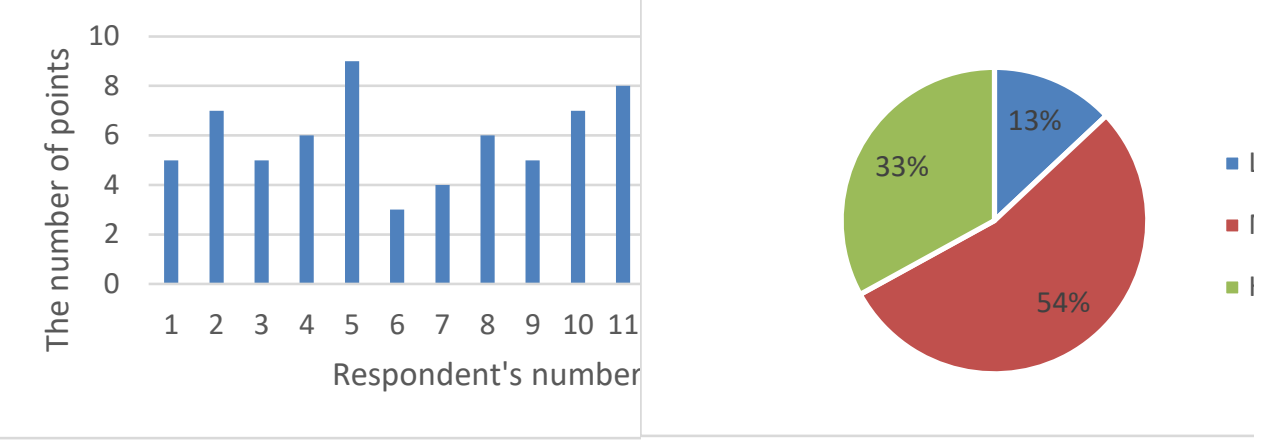

Fig. 5. Distribution of contact center specialists by the number of points and by the level of intensity of this style of behavior in a conflict as a compromise

$33 \%$ of respondents in a conflict situation will be ready to negotiate as a result of which each side will be able to make certain concessions. $54 \%$ of specialists demonstrate an medium level of expression of such style of behavior in a conflict as a compromise. A low level of intensity was noted in $13 \%$ of respondents. In this case these are those specialists who do not want to infringe on their goals and needs for the sake of others but take only their opinion into account.

Distributions of contact center specialists by the number of points and by the level of intensity of such style of behavior in a conflict as evasion are presented in Figure 6.
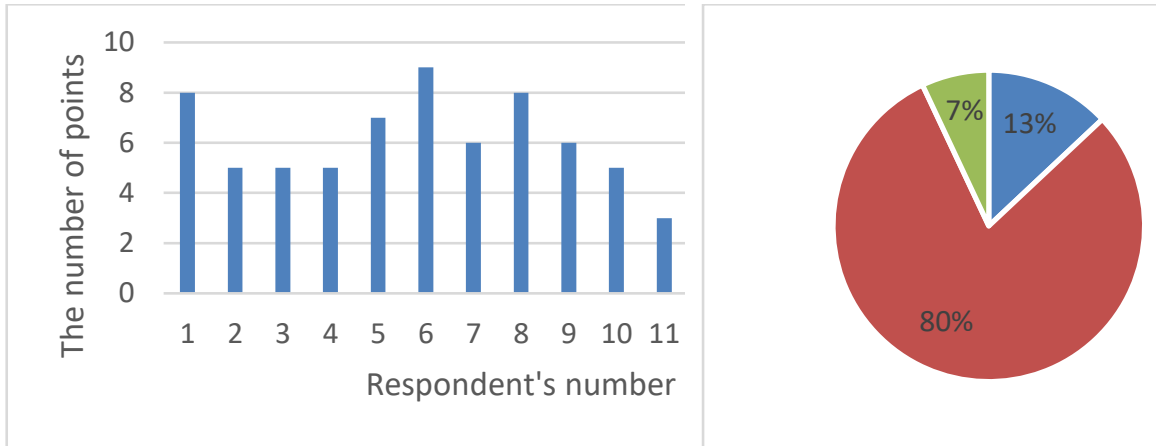

Fig. 6. Distribution of contact center specialists by the number of points and by the level of intensity of such style of behavior in a conflict as evasion and adaptation

The low level of "evasion" found in $13 \%$ of respondents shows that a small proportion of specialists will not adhere to this style of behavior in the conflict. The vast majority ( 80 $\%$ ) of specialists in most conflict situations will exhibit evasion behavior. This style is used when the problem is not so important for the specialist and he doesn't want to spend his time and energy on resolving the conflict. A high degree of conflict avoidance is typical for $7 \%$ of respondents. Typically this behavior occurs when the employee does not assert his rights, doesn't cooperate with colleagues and deliberately avoids conflict.

In the further research was obtained the distribution of employees of the "adaptation" style of behavior the same as for the "evasion" behavior style.

A high level of adaptation noted in $7 \%$ of respondents indicates their ability to sacrifice their own interests for the colleagues. This style of behavior doesn't contribute to a constructive resolution of the conflict and employees who adhere to it are perceived as weak personalities. 
$80 \%$ of respondents are characterized by a medium level of adaptation in conflict situations. That means that specialists of the contact center in a conflict situation in most cases are able to give up their interests in order to please the opponent. But this behavior also cannot lead to a constructive resolution of the conflict because if the sacrifice is not evaluated by the opponent then this creates the basis for the development of emotional conflict.

The severity levels of a particular style of behavior in a conflict situation allow us to divide contact center specialists into two groups: those who seek constructive resolution of the conflict and those who don't seek constructive resolution of the conflict which are presented in table 2 .

Table 2. Distribution of contact center employees by impact on constructive conflict resolution

\begin{tabular}{|c|c|}
\hline \multicolumn{2}{|c|}{ Styles of behaviors in a conflict } \\
\hline $\begin{array}{l}\text { Contributing to its constructive } \\
\text { resolution }\end{array}$ & $\begin{array}{l}\text { Not contributing to its constructive } \\
\text { resolution }\end{array}$ \\
\hline Low level of confrontation $-47 \%$ & $\begin{array}{l}\text { High and medium level of confrontation } \\
-53 \%\end{array}$ \\
\hline $\begin{array}{l}\text { High and medium level of cooperation } \\
-73 \%\end{array}$ & Low level of cooperation $-27 \%$ \\
\hline $\begin{array}{l}\text { High and medium level of compromise } \\
-87 \%\end{array}$ & of com \\
\hline Low level of evasion $-13 \%$ & $\begin{array}{l}\text { High and Medium level of evasion }-87 \\
\%\end{array}$ \\
\hline Low level of adaptation $-13 \%$ & $\begin{array}{l}\text { High and Medium level of adaptation - } \\
87 \%\end{array}$ \\
\hline $\begin{array}{l}\text { Medium degree of manifestation }-46.6 \\
\%\end{array}$ & $\begin{array}{l}\text { Medium degree of manifestation }-53.4 \\
\%\end{array}$ \\
\hline
\end{tabular}

Based on the provided information can be noted that behavior styles in a conflict situation $47 \%$ of the contact center specialists will contribute to a constructive resolution of the conflict. They are characterized by low levels of confrontation, adaptation and evasion, high and medium levels of cooperation and compromise. The behavior of $53 \%$ of specialists will not contribute to a constructive resolution of a conflict situation. They are characterized by low levels of cooperation and compromise, high and medium levels of confrontation, adaptation and avoidance.

Based on the data in Table 2 we can assume that the degree of manifestation of employees who don't contribute to constructive resolution of the conflict characterizes the level of conflict of the team (LCT) and the degree of manifestation of employees who contribute to constructive resolution of the conflict characterizes the level of team coordination (LTC).

The determination of these indicators is possible on the basis of the following ratios:

$$
\begin{aligned}
& \mathrm{LCT}=\mathrm{d}_{,}, \\
& \mathrm{LTC}=\mathrm{d}_{+},
\end{aligned}
$$

where $\quad d_{+}-$the degree of manifestation of employees who in a conflict will demonstrate low levels of confrontation, evasion and adaptation, high and medium levels of cooperation and compromise i.e. adhere to its constructive resolution;

d - the degree of manifestation of employees who in a conflict will demonstrate low levels of cooperation and compromise, high and medium levels of confrontation, adaptation and evasion i.e. adhere to its non-constructive resolution.

So the prevalence of collective conflict reduces its coordination and vice versa. 
The maximum level of coordination (conflict) of the team indicates the complete absence of conflict (coordination) of the team which reflects the extreme aspects of the issue.

An increase of conflict will lead to reduce of effectiveness and manageability of the team because the desire to satisfy only the interests of a certain group of employees to the detriment of all others will lead to decreasing of focus on achieving a common result and as a result to decreasing at the efficiency of the organization as a whole.

Such team will be extremely unstable and prone to a snowball effect in increase of conflict situations.

If conflict has the high level so the less coordination and the more difficult it will be to turn the situation in a positive direction, and therefore, the less manageability of the team.

\section{Conclusion}

The key factor of effectiveness of any organization will not only conflict detection but also competent management of employee behavior in conflict situations.

Conflict management means that sources of conflict are timely identified and immediately prevented. For this it is necessary to influence employees in managerial ways in order to avoid the development of contradictions in the confrontation of conflicting parties.

Decreasing of the level of conflict within the examined structural unit and organization as a whole is possible in the following directions.

Firstly the identification of the level of conflict of employees according to the ThomasKilmann methodology and the definition of LCT or LTC based on expressions (1) or (2).

When in the examined team more employees show constructive behavioural styles in case of conflict we can conclude that there will be highly possible to drive probable negative situation to a positive direction taking into account the interests of all conflict participants.

This will be the primary task of the head of the structural unit or organization as a whole depending on the characteristics of the examined team.

Like any authoritative person who owns of real power in the team he must identify all the causes, factors, circumstances that become a real conflict and help create the conditions for its constructive resolution taking into account the interests of all participants of the opposing parties.

Currently there is a slight advantage in the call center of JSC "DOM.RF" in favor of specialists who will not seek to resolve the current conflict situation constructively. The level of conflict of examined team is $53.4 \%$, and the level of consistency is $46.6 \%$ in accordance with expressions (1) and (2).

From the point of view of the obtained LCT and LTC values the examined team is almost at the center between conflict and coherence. There is still a real opportunity to direct any conflict situation in a positive direction. But as conflict increases negative trends in relationships will accumulate and opportunities for constructive resolution will decline. Therefore there is an objective need for the following activities.

Secondly it makes sense to conduct a psychological diagnosis of personality conflict during the hiring for a vacant position. For specialists of the call center of JSC "DOM.RF" such a diagnosis is not carried out [8]. Its using would reduce hiring errors and reduce the level of conflict of any team.

As you know the psychological component of the employees' relationships of any team has a significant impact on the achieved results. Therefore within any organization a closer attention should be paid to it.

In accordance with this thirdly in order to control the behavior of employees in a conflict situation it is necessary to conduct psychological training for employees of the structural unit or organization as a whole. It will allow for participants to:

- impartially evaluate a conflict situation; 
- adjust their behavior in the direction of reducing conflict;

- increase the level of coordination and cohesion of the team [9].

\section{References}

1. A. G. Zdravomyslov, Sociology of Conflict: Russia on the way to overcoming the crisis: A training manual for students of High Education School, 320 (Moscow, Aspect-Press, 1995)

2. V. V. Davydova, A. V. Zaporozhets, B. F. Lomov, etc., Psychological Dictionary, 448 (Moscow, Scientific Research Institute of General and Pedagogical Psychology of the Pedagogical Sciences Academy in the USSR, 1983)

3. A. Ya. Antsupov, A. I. Shipilov, Dictionary of Conflictologist, 656 (Moscow, Eksmo, 2010)

4. B. I. Hassan, Psychotechnics of conflict and conflict competence, 157 (Krasnoyarsk: Mental Health Fund, 1996)

5. G. Simmel, Selected Works, 440 (K: Nika-Center, 2006)

6. L. Coser, The Functions of Social Conflict. London: Routledge \& Paul (1968)

7. S. V. Kardashina, N. V. Shangina, "Psychometric characteristics of the russian version on the Thomas-Kilmann questionaire («Thomas-Kilmann conflict mode instrument TKI-R»)" Pedagogical Education in Russia, 11, 216-228 (2016)

8. E. L. Kandybina, D. A. Lyakhovskaya, "Organization of the recruitment process in the unified service center of «DOM. RF» JSC", Actual problems of daily activities of departments, improving the theory of organization and personnel management: Collection of articles based on the materials of the VI Scientific and practical conference «Youth readings dedicated to the memory of Yuri Gagarin». - Voronezh: MTRC of Air Force «Air Force Academy named after Prof. I. E. Zhukovsky and Y. A. Gagarin», 21 23 (2019)

9. N. A. Nagibina, I. A. Griboedova, "Team building in the organization's personnel management system". Topical questions of personnel management in organizations: Collection of articles based on the materials of the Scientific and practical conference, 47-53 (Voronezh, Voronezh state technical university, 2013)

10. L. Pushkareva, M. Pushkarev, E3S Web of Conferences, 210, 13041 (2020) doi:10.1051/e3sconf/202021013041 